\title{
Analysis of the Impact of Live Streaming and Short Video Industry in China
}

\author{
Peng Xinbei ${ }^{1, a}$ Xue Qianru ${ }^{2, b}$ \\ ${ }^{1}$ Department of Economy and Trade, South China Business College Guangdong University of Foreign Studies, \\ Baiyun, Guangzhou, Guangdong, China \\ ${ }^{2}$ Department of Economy and Trade, South China Business College Guangdong University of Foreign Studies, \\ Baiyun, Guangzhou, Guangdong, China \\ a792576423@qq.com \\ b450241170@qq.com
}

\begin{abstract}
Based on the background of the exploration of the COVID-19 and booming live streaming and short video industry, this paper analyses the impact on society and other industries, and puts forward the prospect of its development in the future.
\end{abstract}

Keywords: Live streaming and short videos industry, Impact

\section{BACKGROUND}

\subsection{A change of needs on both sides of the supply and demand because of the COVID-19 exploding}

Affected by the COVID-19 in 2020, consumers, whose lifestyles and the ways of entertainment has shifted gradually from offline to online, prefer short videos and live streaming with content rich variety, which play a significant role in their daily life. A new consumption mode is greatly satisfying the needs of people to access to external information and entertainment.

In addition, a large number of entities and offline industries have suffered a severe loss, resulting in the situation that they were unable to operate normally and have pressed the pause button. It is indispensable and urgent for enterprises to find a new feasible sales channel. Fortunately, the live streaming and short videos industries provide a new platform for real economic transition to the internet.

\subsection{Booming live streaming and short video industry}

With the progress of Internet technology and the continuous improvement of people's spiritual life, China's live streaming and short videos industry has ushered into a booming development. According to 45 th Statistical report on the Internet Development in China published by CNNIC, as of March 2020, the number of short videos users was 773 million, accounting for $85.6 \%$ of the total Internet users. ${ }^{[1]}$ According to iiMedia, it is estimated that by the end of 2020, there will be 526 million live streaming users and more than 700 million short video users in China. ${ }^{[2]}$ In the future, it is estimated that the market scale will keep development owing to the fact that it is indispensable way for people to entertain online.

\section{POSITIVE IMPACT ON OTHER INDUSTRIES IN CHINA}

It is both opportunities and challenges for the marketing strategy of traditional industry. In fact, we can see the new technique has been working so much. Specific examples are as follows:

\subsection{Live e-commerce helps alleviate poverty in rural area of China}

In recent years, a new trend and new bright spot by means of live streaming and short videos makes up the shortcomings of traditional agricultural product marketing with innovation. It has played a positive role in alleviating the difficulty of selling, helping the development of industry and increasing farmers' income. [3] 
In particular, the enterprises, sale agencies and government departments have to change their mind and get a new technique, such as live streaming commerce or short video in order to get rid of the crisis, resulting from the fact that the amounts of sale have sharply reduced during the COVID-19 period. Tens of thousands of vegetable greenhouses in the country were instantly turned into direct broadcasting room. Mayors, county heads and township heads bring goods to be social media influencers, as well as invite famous anchors to raise more attention, which make them find a new way to promote and sell agricultural products.

\subsection{Live streaming and short videos help education industry innovate}

Online teaching by live streaming and short videos breaks the traditional ways of education with restrictions of time and space. Due to exploration of the COVID-19, teachers and students are unable to go back to school for normal learning, while it is advocated by government that it won't stop us from learning even if we can't go to school. At the same time, with the opportunity of flourishing live streaming and short videos industry, online teaching platforms began to promote courses in this way. What 's more, diversified methods such as famous teachers and interesting teaching classes were used to gather the web traffic, rapidly forming a new business form of education. For teachers, the combination with these new ways in teaching, makes them become network anchors who have more concern about how to rapidly adapt this all-new role and ensure the teaching quality. ${ }^{[4]}$ In terms of students, the selections of contents are freer and studying is more convenient.

On the other hand, compared with traditional offline education, live streaming and short videos can broaden the scope of audience wider range, which can alleviate the problems of uneven distribution of educational resources. For example, Tsinghua University, Peking University and other well-known universities have also begun to open live streaming courses for the whole people on the platform.

\subsection{Traditional e-commerce upgrading and transformation with new mode to solve the main problems}

In terms of the display of commodity information, videos are more abundant than pictures and texts. The anchors can play the role like offline shopping guide and interact with the audience in real time. In addition, with the participation of Internet Celebrities and stars, live shopping will be more popular.

For e-commerce, for the sake of increasing consumers trust and attracting buyers to watch, short videos can show the processing process of production and characteristics of goods in the public, while live streaming can be used to promote and sell new products. The two tools maximize the sales volume of sellers. The short videos platforms have a large fans flow, which can effectively improve the conversion rate of live streaming and facilitate the traffic monetizing of the platform. Besides, it's easier to know about the anchor's life through interacting with them by the short video, thereby it can shorten the distance between the anchors and the fans, such as likes and comment.

\subsection{The main ways of China's tourism recovery}

In an attempt to recover from a disastrous first quarter, in the spring of 2020, all of China's leading OTAs started live streaming. These online broadcasts not only attracted huge audiences, but they also turned the revenue taps back on, marking the first stage in China's tourism recovery. For example, the CEO of Qunar has been live streaming from domestic destinations since April, bringing in an average RMB16 million per broadcast. Likewise, Alibaba's online travel marketplace Fliggy has seen a surge in businesses and influencers live streaming through the platform. This is really a never-before-seen phenomenon for China's online travel market.

\subsection{A faster way of spreading news and information}

During the COVID-19 period, mastering the scientific knowledge of prevention has become an urgent need of the public. At the same time, the short videos and live streaming platforms have the advantages of wide dissemination range, which can effectively promote the popularization of science during this period. Compared with traditional media by text reports, online platform is timelier and reaches a wide range of users, which plays an important role in the dissemination of authoritative news and information. What's more, these new ways enable users to have a deeper understanding of the situation, and make the front-line information better transmission.

\section{NEGATIVE IMPACT OF LIVING STREAMING AND SHORT VIDEO INDUSTRY DEVELOPING}

The booming live streaming and short video industry is a double-edged sword. Although it has brought new opportunities to other industries, it will also cause social disorders and other negative effects due to the immature development of this industry. What's more, it still needs to be improved in terms of standardization and safety. 


\subsection{Low threshold makes uneven quality of contents}

Most short video and live streaming platforms are based on User Generated Content (UGC) with low production threshold, that is, users can publish their own original contents through internet platforms with less restriction. The situation that good will be driven out by bad money will easily emerge due to three factors as follow: First, platforms are lack of regulatory review process for the dissemination of the contents. Second, laws and regulations are uncompleted. Finally, there exists defects of effective mechanisms to punish violations of inappropriate contents. In order to meet the needs of curious hunters, many platforms have delivered a variety of bad content such as money worship, sexual suggestion, violence, etc. The behaviours resulted from their profit-oriented mentality will easily mislead audiences to form wrong values and create a bad social atmosphere.

\subsection{The information security system of platform is not perfect leading to easy information disclosure of users}

One of the major features of live streaming and short videos is the form of presentation based on personal life scenes, images and sounds. If the platform has insufficient supervision on network information security, there will be potential dangers of users' privacy leakage. In addition, personal information protection awareness of users is very weak. Many individual users share their lives, family and friends with pictures, short videos, live broadcasts, and text on various social platforms. In the process of information transmission, private information of oneself is often inadvertently leaked, and information is easily obtained by some malicious people.

\subsection{False data mislead consumers into consumer behaviours}

Live streaming platforms always rely on celebrity effect to attract popularity. In order to improve merchandise sales, the businesses adopt many measures, such as using click farming, making fake followers and reviews as well as other hidden rules of industry, resulting in data fraud. Commodity consumption data usually is displayed by the platform, and consumers review to determine whether the product is worth buying. The fraudulent behaviour of merchants will mislead consumers, leading to an awful sense of real purchase experience. The behaviour, focusing on quantity but ignoring quality, will corrupt the industry's ethos so that the businesses are difficult in sustainable development.

\subsection{The lack of a sound regulatory system and means}

Live streaming and short video industry is a fastgrowing new business form, lacking a complete regulatory system and means. Business reputation is so uneven that it is prone to bugs in after-sales service management. Under the aggressive growth momentum of influencer marketing, many problems emerge in endlessly, such as inconsistent goods with the sample, copycat products and selling uncertified products. The quality of goods cannot be guaranteed due to lack of control. Some merchants use Alipay, WeChat payment and other transaction methods to escape the supervision of third-party platforms. If consumers find some problems, it is difficult for them to get evidence through a third-party platform, or directly contact the anchor or merchant to reflect and solve some problems.

\section{CONCLUSION}

With the gradual advancement of 5G technology research and network development, social restrictions and limitations on time and space are gradually broken. The live streaming and short video industries will combine more application scenarios in other industries to achieve more innovations and breakthroughs at the industrial ecological level. Therefore, the boundaries of the live streaming and short video industries will continue to expand, and the market scale will keep rising.

As a new media carrier, live streaming and short videos can inject new vitality into many industries. But the industry is still in the early stages of development of trade routes, industry value needs to be further explored. This article analyses the positive impact of the booming of live streaming and short video on China's social economy and various industries. At the same time, it find the problems in the development process of live streaming and short video. However, we believe that with the popularization of new technologies such as $5 \mathrm{G}$, Internet of Things, artificial intelligence, and block chain. What's more, the improvement of relevant policies and regulations, the current development problems of live streaming and short video will be solved. More standardized platforms will continue to improve. Trough systematic screening platform, scientific and technical supervision, the quality of contents will be gradually improved. Live streaming and short video will have more contacts with other industries, accelerating the pace and depth of integration of various industries. To sum up, they will create unlimited possibilities in the future.

\section{ACKNOWLEDGMENTS}

Thanks to China Internet Network Information Center for providing us with data assistance. Thanks for iiMedia Research offering research on live streaming and short video to provide us materials. Thank you CPCI for 
giving us the opportunity to express our academic views. In this together thanks!

\section{REFERENCES}

[1] China Internet Network Information Center, The 45th China Statistical Report on Internet Development.

DOI:http://www.cnnic.net.cn/hlwfzyj/hlwxzbg/hlw tjbg/202004/t20200428_70974.htm.

[2] iiMedia Research, 2020-2025 Chiina Short Video/Live Sound Card Equipment Field Application Development White Paper. DOI:https://www.iimedia.cn/c1020/74816.html.

[3] Rihui,OY,(2020) "Live streaming +" economy helps farmers in the network against "COVID-19". Economic information daily.

[4] Shen,J, Xiaomei,L, Qingyang,M, Qingyue,H, Mingyang,S, (2020)Analysis on the current situation and countermeasures of Network broadcast education in China. Education modernization, pp.175-178. 